\title{
54 CONGRESO INTERNACIONAL DE AMERICANISTAS
}

Viena, 15 - 20 julio de 2012

http://ica2012.univie.ac.at/

http://ica2012.univie.ac.at/es/simposios-pre-aceptados/8-lingueistica-literatura-y-medios/

Propuestas de comunicaciones hasta el 31 de agosto de 2011

El 54 Congreso Internacional de Americanistas tendrá lugar en Viena del 15 al 20 de julio de 2012. El tema general de este encuentro es Construyendo Diálogos en las Americas.

Simposios preaceptados de la sección de Lingüística, Literatura y Medios / Linguística, literatura e mídia (Responsable / Responsável: Kathrin Sartingen):

450 - Ficção contemporânea americana: modos de ler 452 - Lenguas y variedades en contacto: un desafío para las teorías del lenguaje 459 - Variación histórica y variación inducida por contacto en las lenguas Tupí 480 - Representaciones de la revolución en el cine latinoamericano 505 - Lenguas en contacto en la América Latina en el tiempo de la globalización: ¿supervivencia o extinción?

(C) 2011 Círculo de Lingüística Aplicada a la Comunicación (clac) 46, 125-126.

Universidad Complutense de Madrid. ISSN 1576-4737. http://www.ucm.es/info/circulo 
535 - Cultura en la nueva españa: crónica, retórica y semántica

611 - Lenguas indígenas de América. Estudios descriptivos-tipológicos y sus contribuciones para la linguística teórica

613 - Entre conversión, inversión y subversión: Los textos en lenguas amerindias escritos por autores indígenas en la época colonial

617 - Diálogos en la Panamazonía: Literatura, Cultura y Sociedad

623 - Representación de lo indígena en el cine contemporáneo de América Latina: lenguas, culturas, tradiciones y mitos

654 - Arawakan linguistic and cultural identities

687 - Maya languages and histories

710 - Un diálogo entre el pasado y el presente de los huastecos de Veracruz y San Luís Potosí

745 - Lenguas y culturas andinas en diálogo: identidad $\dot{¿}$ diversidad $\dot{\mathcal{C}}$ hibridez $\dot{\chi}$ globalización

759 - Escribir la infancia: entre temas y juegos

817 - El transnacionalismo: Condiciones de producción, representación y recepción en el cine contemporáneo.

843 - Políticas públicas de comunicación y democracia en Iberoamérica

845 - Audio-visual dialogues

890 - Literatura e cinema: negociações, trânsitos e apropriações

894 - The effects of animacy hierarchies in native languages of the Americas

932 - The Language of Space in Latin American Indigenous Languages

938 - Hechos y datos de los pueblos del Gran Chaco: diálogo histórico entre la antropología, la sociología, la lingüística, y la arqueología para un esclarecimiento del estado actual de las poblaciones originarias de la región.

1086 - Caminos, fronteras y exilios latinoamericanos en el cine y la literatura

1708 - Narrativas, relatos e testemunhos no circuito ibero-americano 